\title{
Experimental Study of Steel Fiber Concrete Slabs Part I: Behavior under Uniformly Distributed Loads
}

\author{
Ali Ellouze, ${ }^{1,2)}$ Mongi Ben Ouezdou, ${ }^{1,3)}$ and Mohammed Ali Karray ${ }^{1)}$
}

\author{
(Received July 9, 2010, Revised October 14, 2010, Accepted October 19, 2010)
}

\begin{abstract}
This article aims to study the effects of adding steel fibers to concrete on the mechanical behavior of steel fiber concrete (SFC) slabs. After formulating the SFC, an experimental work was, first, conducted on $160 \times 320 \mathrm{~mm}$ cylindrical specimens and $70 \times 70 \times 280 \mathrm{~mm}$ prisms. Then, this study was carried out on 20 rectangular $1,100 \times 1,100 \times 60 \mathrm{~mm}$ small slabs submitted to a distributed load. Two types of fibers with hooked ends were used: long fibers (LF) of a length of $50 \mathrm{~mm}$ and short fibers (SF) of a length of $35 \mathrm{~mm}$. The studied parameters are compressive and tensile strengths and Young's modulus. Plain concrete (PC) small slabs were also prepared to be compared to the SFC specimens. The results showed that the compressive strength of SFC increased up to $25 \%$ while the splitting tests showed an improvement of the SFC reaching $45 \%$. Tests on SFC small slabs also showed that a smaller deflection is obtained with respect to PC, which indicates an improvement in strength (up to $100 \%$ ), in ductility and in resistance to cracking. The LF gives a better improvement in strength than the SF for a $70 \% \mathrm{~kg} / \mathrm{m}^{3}$ of steel proportioning.
\end{abstract}

Keywords: slabs, steel fibers, concrete, workability, strength.

\section{Introduction}

The introduction of the steel fiber concrete (SFC) into the technology of industrial flooring slabs is the result of certain difficulties encountered by the reinforced concrete solution. In fact, the reinforcement can play its role, notably the control of cracking generated by the mechanical impacts and the prevented shrinkage, only when it is correctly positioned in the paving slabs, which is a very uncommon case. The use of fibers in industrial slabs allows the transfer of forces through cracks and openings, thus generating a ductile behavior. Because of the capacity of large rotations with simultaneous significant bearing capacity, investigations of SFC slabs are necessary for the behavior in bending, punching effect and crack openings.

Many researchers were interested in studying the use of SFRC in slab applications. In 1991 , Vondran ${ }^{1}$ indicated that the primary steel fiber reinforced concrete (SFRC) slab applications are for factory floors and industrial floors, where damaging dynamic and concentrated loads require more reinforcing. He also stated that SFRC slabs are used in commercial floors, where crack and

\footnotetext{
${ }^{1)}$ Civil Engineering Laboratory, National Engineering School of Tunis, BP 37, 1002 Tunis-Belvédère, Tunisia.

Email: mongi.benouezdou@enit.rnu.tn.

${ }^{2)}$ Dept. of Civil Engineering, Higher Institute of Technological Studies, BP 88A, 3099 El Boustan, Sfax, Tunisia.

${ }^{3)}$ Dept. of Civil and Environmental Engineering, College of Engineering and Architecture, University of Nizwa, PO Box 33, 616 Birkat Al Mouz, Nizwa, Sultanate of Oman.

Copyright (c) 2010, Korea Concrete Institute. All rights reserved, including the making of copies without the written permission of the copyright proprietors.
}

fatigue resistance is needed. In 1996, Bakht and $\mathrm{Mufti}^{2}$ have tested small and full-scale SFC deck slabs for bridges without reinforcement. Newhook and $\mathrm{Mufti}^{3}$ presented a SFC deck slab of the Salmon River Bridge in Canada, constructed in 1995, as to avoid $\mathrm{RC}$ corrosion. For comparison, the bridge had one span in SFC and one span in an ordinary RC. Later on, Sargent et al. ${ }^{4}$ also presented tests on SFC deck slabs of the Lindquist bridge (British Columbia, Canada), constructed in 1997.

Since 1999, Marti et al. ${ }^{5}$ presented a harmonized test procedures for SFRC for circular and rectangular slabs under point loading. In Europe and in 2001, Destree ${ }^{6}$ have tested $160 \mathrm{~mm}$ thick SFRC slab supported by a $3.1 \times 3.1 \mathrm{~m}$ pile grid. He concluded that the quality of a completed slab is a function of both sound design and efficient installation. Recently, Ošlejs ${ }^{7}$ gave an overview of the experience from the Baltics and Scandinavia in the use of the SFRC slabs over piles (on to 2.5 to $6 \mathrm{~m}$ grids). Falkner et al. ${ }^{8}$ have made a comparative study of PC and SFRC of ground slab by verifying the ability of the SFRC to support loads even after the formation of cracks. Barros and Figueiras ${ }^{9}$ studied the behavior of $1,800 \times 500 \times 75 \mathrm{~mm}$ slab strips, using $0,30,45$ and $60 \mathrm{~kg} / \mathrm{m}^{3}$ of steel fibers. These strips were reinforced with a $2.7 \mathrm{~mm}$ diameter mesh wire. They studied the crack pattern and determined the failure load. Khaloo and Afshari ${ }^{10}$ studied the flexural behavior of small SFRC slabs by considering the influence of length and volumetric percentage of steel fibers on energy absorption. They concluded that addition of fibers did not significantly increase the ultimate flexural strength of SFRC slabs, but it improves the energy absorption capacity of the slabs. Recently, Sorelli et al. ${ }^{11}$ studied the structural behavior of the SFRC slabs on ground under a concentrated load. They concluded that a relatively low content of steel fibers effectively enhances the load-carrying capacity of 
the slabs on ground and that a volume fraction of steel fibers higher than $0.38 \%$ slightly improves the ultimate load but remarkably enhances the slab ductility.

It is known that the main use of SFC is to be employed in the ground slab of industrial floors. The aim of this paper is to investigate the behavior of such slabs under different loading condition. At first a presentation of the optimal design is chosen. Then, the work is directed towards the study of the behavior of SFC small slabs. In this part I of the paper, the study will be focused on the behavior of the slabs subjected to distributed loads. The behavior under such load represent a new study in this field.

\section{Formulation}

The formulation of concrete is usually set to achieve three main goals: Obtain a good mechanical strength, get an adequate rheology for implementation, and limit the undesirable side effects.

\subsection{Materials}

In this study, the following materials of construction were used:

- Cement CPI 32.5, with an absolute density of $3.1 \mathrm{~g} / \mathrm{cm}^{3}$.

- Siliceous sand with an absolute density of $2.63 \mathrm{~g} / \mathrm{cm}^{3}$, with an equivalent of sand of $78 \%$, a value of methylene blue of 0.8 and a fineness modulus of 2.26 .

- Gravel (size of 4/12 and 12/16), absolute density of $2.72 \mathrm{~g} / \mathrm{cm}^{3}$, an absorption coefficient of water of 0.85 and Los Angeles coefficient equal to 25 .

The employed fibers, during this study, were Sika hooked ends steel fibers (Dramix) with two types of length:

- Long fibers (LF), reference: RC-80/50-BN: length $50 \mathrm{~mm}$ and diameter $0.62 \mathrm{~mm}$.

- Short fibers (SF), reference: RC-65/35-BN: length $35 \mathrm{~mm}$ and diameter $0.55 \mathrm{~mm}$.

\subsection{Optimization of the concrete without fibers}

Knowing that fibers decrease the SFC workability, and taking into account the work of Rossi et al., ${ }^{12-17}$ the following experimental approach was adopted in order to design the concrete without fibers:

- Varying the gravel/sand ratio $(\mathrm{G} / \mathrm{S})$ to obtain a relation between the optimal workability and a good strength.

- Adjusting the quantity of super-plasticizer to obtain a dosage giving the optimal strength (1.5\% of cement proportioning) and a good workability.

Figures 1 and 2 show the evolution of the flow time, the slump and the compressive strength as a function of the $\mathrm{G} / \mathrm{S}$ ratio. These figures indicate that the optimal of $\mathrm{G} / \mathrm{S}$ ratio is equal to 1.2. Then the resulting of the optimal composition of the plain concrete (PC) without fibers is obtained and it is presented in Table 1.

\subsection{Optimization of the SFC}

From this formulated PC, the SFC was obtained by incorporating fibers. $160 \times 320 \mathrm{~mm}$ and $70 \times 70 \times 280 \mathrm{~mm}$ specimens have been therefore made. Flexural tension tests has been used for the $70 \times 70 \times 280 \mathrm{~mm}$ specimens according to the French standards. ${ }^{18}$ The results of these tests are presented in Table 2. These results show that the mechanical behavior of concrete has clearly improved $\left(\approx 25 \%\right.$ ) when using a proportioning up to $30 \mathrm{~kg} / \mathrm{m}^{3}$ of

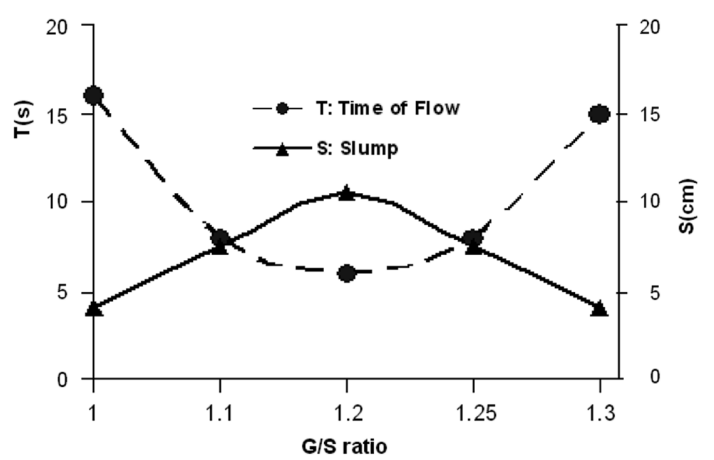

Fig. 1 Time of flow and slump vs G/S ratio curves.

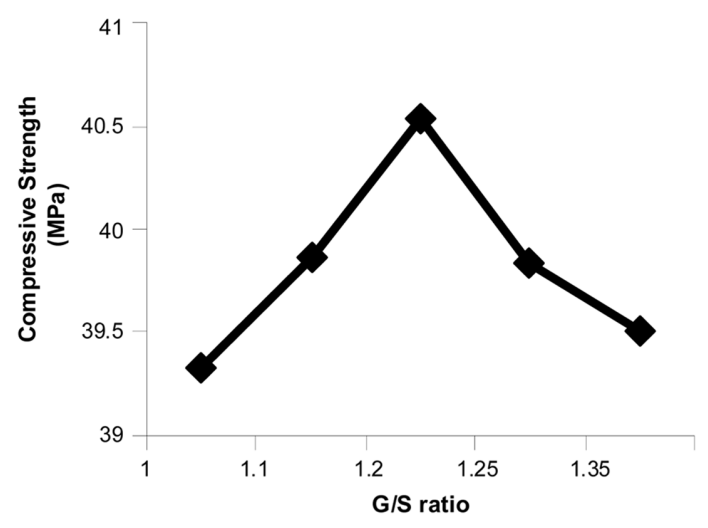

Fig. 2 Compressive strength vs G/S ratio curve.

Table 1 Composition of the plain concrete (PC) (for $1 \mathrm{~m}^{3}$ ).

\begin{tabular}{c|c}
\hline Gravel/Sand $(\mathrm{G} / \mathrm{S})$ & 1.2 \\
\hline \hline water/cement $(\mathrm{W} / \mathrm{C})$ & 0.4 \\
\hline Cement CPI 32.5 (kg) & 400 \\
\hline Washed sand $(\mathrm{kg})$ & 837 \\
\hline Gravel $(\mathrm{Kg})$ & 1,005 \\
\hline Super-plasticizer (Sika Viscocrete) 5400F (kg) & 6 \\
\hline
\end{tabular}

long fibers. But, the mechanical strength has decreased ( $\approx 20 \%$ ) when the long fibers density is included between $30 \mathrm{~kg} / \mathrm{m}^{3}$ and $50 \mathrm{~kg} / \mathrm{m}^{3}$. However, when using short fibers, the mechanical behavior of concrete has also improved $(\approx 45 \%)$ until a density of $40 \mathrm{~kg} / \mathrm{m}^{3}$ of short fibers, and then it fell when using $50 \mathrm{~kg} / \mathrm{m}^{3}$. This is explained by the disturbance of the granular arrangement caused by the fibers incorporation. The formulation was redone using the same experimental method, by introducing the fibers proportioning while searching the $\mathrm{G} / \mathrm{S}$ ratio.

\subsection{Formulation of a concrete reinforced with $70 \mathrm{~kg} / \mathrm{m}^{3}$ steel fibers}

An experimental study was carried out on the SFC formulations using a higher fiber density of $70 \mathrm{~kg} / \mathrm{m}^{3}$. Thus, three $160 \times 320 \mathrm{~mm}$ specimens and three $70 \times 70 \times 280 \mathrm{~mm}$ specimens have been prepared. The results of the workability, the compressive strength and the tensile by flexure tests are presented in Table 3. These results show that the G/S ratio which leads to the best workability and to a good strength (compressive and traction by flexure) is equal to 1 for LF or SF.

It is imperative to distinguish: 
Table 2 Results of compression and tensile tests (by splitting and by flexure) (MPa) for a G/S = 1.2.

\begin{tabular}{|c|c|c|c|c|c|c|c|c|c|c|c|c|}
\hline \multirow{2}{*}{ Tests } & \multirow{2}{*}{$\begin{array}{l}\text { Age } \\
\text { (days) }\end{array}$} & \multirow{2}{*}{$\mathrm{PC}$} & \multicolumn{5}{|c|}{ Proportioning for LF: RC $80 / 50-\mathrm{BN}\left(\mathrm{kg} / \mathrm{m}^{3}\right)$} & \multicolumn{5}{|c|}{ Proportioning for SF: RC 65/35-BN $\left(\mathrm{kg} / \mathrm{m}^{3}\right)$} \\
\hline & & & 10 & 20 & 30 & 40 & 50 & 10 & 20 & 30 & 40 & 50 \\
\hline \multirow{2}{*}{$\begin{array}{l}\text { Compressive } \\
\text { strength }\end{array}$} & 7 & 37.2 & 42.5 & 42.8 & 43.2 & 41.9 & 35.2 & 38.6 & 38.9 & 42.2 & 44.8 & 42.6 \\
\hline & 28 & 44.6 & 48.3 & 49.0 & 49.5 & 46.7 & 37.8 & 45.0 & 46.5 & 49.2 & 54.5 & 48.6 \\
\hline \multirow{2}{*}{$\begin{array}{l}\text { Resistance to } \\
\text { traction by splitting }\end{array}$} & 7 & 2.8 & 3.4 & 3.6 & 4.0 & 3.8 & 3.5 & 3.1 & 3.1 & 3.7 & 4.4 & 4.3 \\
\hline & 28 & 3.2 & 3.6 & 3.8 & 4.5 & 4.3 & 3.9 & 3.3 & 3.4 & 4.1 & 4.8 & 4.7 \\
\hline \multirow{2}{*}{$\begin{array}{l}\text { Resistance to } \\
\text { traction by flexure }\end{array}$} & 7 & 5.6 & 5.9 & 6.1 & 6.6 & 6.0 & 5.1 & 5.7 & 5.9 & 6.8 & 7.2 & 6.9 \\
\hline & 28 & 6.5 & 7.3 & 7.5 & 7.6 & 7.2 & 6.5 & 6.4 & 6.9 & 7.7 & 8.6 & 8.0 \\
\hline
\end{tabular}

Table 3 Results of the workability, the compressive strength and the tension by flexure tests.

\begin{tabular}{|c|c|c|c|c|c|c|}
\hline \multirow{2}{*}{$\begin{array}{l}\text { Nature of } \\
\text { the concrete }\end{array}$} & \multirow{2}{*}{$\mathrm{G} / \mathrm{S}$ ratio } & \multirow{2}{*}{ Flow time (s) } & \multirow{2}{*}{$\begin{array}{l}\text { Compressive } \\
\text { strength }(\mathrm{MPa})\end{array}$} & \multicolumn{3}{|c|}{ Tensile strength by flexure } \\
\hline & & & & At Failure (MPa) & Max (MPa) & Fiber (MPa) \\
\hline$\overline{\mathrm{PC}}$ & 1.20 & 3 & 40.6 & 6.3 & 6.3 & 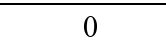 \\
\hline \multirow{4}{*}{ SFC $70 \mathrm{SF}$} & 1.10 & 13 & 47.2 & 7.4 & 7.4 & 6.3 \\
\hline & 1.05 & 11 & 46.1 & 7.5 & 7.5 & 7.4 \\
\hline & 1.00 & 9 & 49.1 & 8.6 & 8.6 & 8.5 \\
\hline & 0.90 & 16 & 47.3 & 7.6 & 7.6 & 6.4 \\
\hline \multirow{4}{*}{ SFC $70 \mathrm{LF}$} & 1.10 & 22 & 40.5 & 7.1 & 7.2 & 7.2 \\
\hline & 1.00 & 11 & 48.7 & 8.1 & 9.2 & 9.2 \\
\hline & 0.95 & 12 & 45.9 & 7.7 & 8.7 & 8.7 \\
\hline & 0.90 & 26 & 45.5 & 7.6 & 8.3 & 8.3 \\
\hline
\end{tabular}

- the SFC having an increasing behavior, for which the rupture stresses ( $\sigma_{\text {Rupture: }}$ stresses caused by the concrete cracking) are less than the maximum stresses $\left(\sigma_{\mathrm{Max}}\right.$ : maximum stress which is equivalent to the adherence of fibers to concrete, noted Fiber, in the cracked part). In this case, we observe multiple cracking till the maximum effort support the structure and consequently, the computation of the resistant capacity of the plastic section as a function of the plastic deformation allows designing the structure.

- and the SFC having a decreasing behavior, for which the rupture stress $\left(\sigma_{\text {Rupture }}=\sigma_{\text {Max }}\right)$ is larger than the fibers stress $\left(\sigma_{\text {Fiber }}\right)$. In this case, the bearing capacity of a SFC determinate structure is linked to unique crack propagation. The calculation of the bearing capacity of a cracked section as a function of crack opening may then allow designing a structure.

Fig. 3 illustrates the shape curves of the three points bending stress variation as a function of the deflection. The results show that for the formulation of short fibers with proportioning less than $70 \mathrm{~kg} / \mathrm{m}^{3}$, the trend of strength of the SFC is still decreasing. We can explain this phenomenon by an insufficient anchorage length between fibers and concrete. On the other hand, for long fibers with proportioning less than $30 \mathrm{~kg} / \mathrm{m}^{3}$, the SFC also exhibits a decreasing behavior due to an insufficient amount of fiber to withstand the load after concrete failure, while for the proportioning of $70 \mathrm{~kg} / \mathrm{m}^{3}$ the behavior SFC is increasing.

The evolution of the three points flexural strength as a function of the deflection value is illustrated in Fig. 4. This figure illustrates the forces versus deflection for the PC, for the SFC with $70 \mathrm{~kg} / \mathrm{m}^{3}$ steel fibers (SFC70), for the SFC with $30 \mathrm{~kg} / \mathrm{m}^{3}$ steel fibers (SFC30), and for the SFC with $40 \mathrm{~kg} / \mathrm{m}^{3}$ steel fibers (SFC40). This figure shows that short steel fibers have the capacity to sew cracks and delay their appearance and their propagation. These

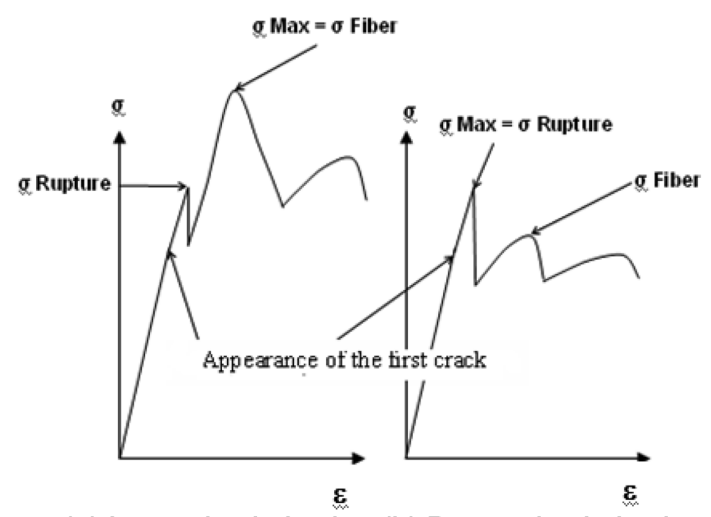

(a) Increasing behavior (b) Decreasing behavior

Fig. 3 Stress-deflection characteristic curves.

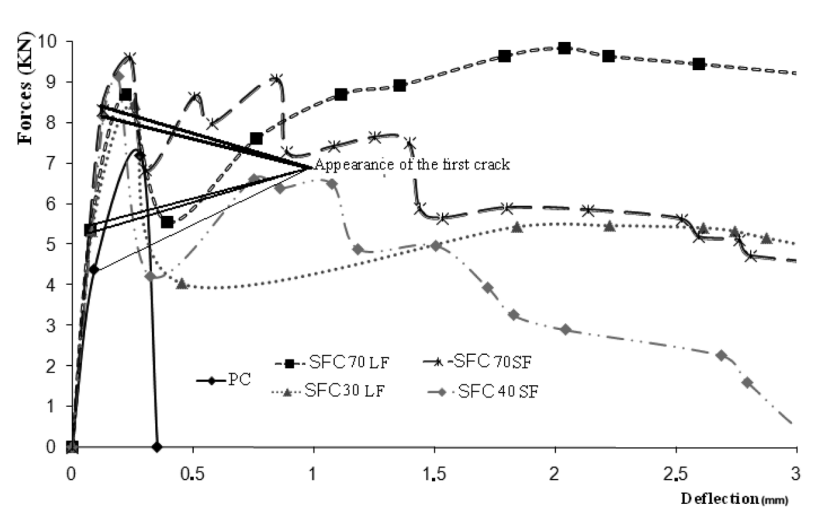

Fig. 4 Three points flexural strength vs deflection curves.

fibers of SFC increase the ultimate strength (up to 35\%), improve the elastic slope and reduce the damaged parts (explained by the 
mixture law). Thus, concrete failure switches from a brittle to a ductile mode type. These effects were also noticed for the LF case, but in a less attenuated way ( $\approx 20 \%$ ). On ther hand, the effect of LF results in a better ductility and deformation after the concrete failure.

\section{Experimental study}

\subsection{Experimental set-up}

An experimental program was developed in order to quantify the contribution of fibers to the SFC slabs. Twenty $1,100 \times$ $1,100 \times 60 \mathrm{~mm}$ small slabs simply supported on their four sides were prepared to study the flexure characteristics under a uniformly distributed load. The tests were carried out using a bending machine. A uniform loading is applied through water pressure beneath the slab as illustrated in Fig. 5. The deflection is measured at the center of the small slabs.

\subsection{Results and discussions}

The stresses-deflection curves are presented in Figs. 6 and 7 for various types of concrete. The variation of stresses as a function of the deflection, when these deflections are small (less than $3 \mathrm{~mm}$ ),
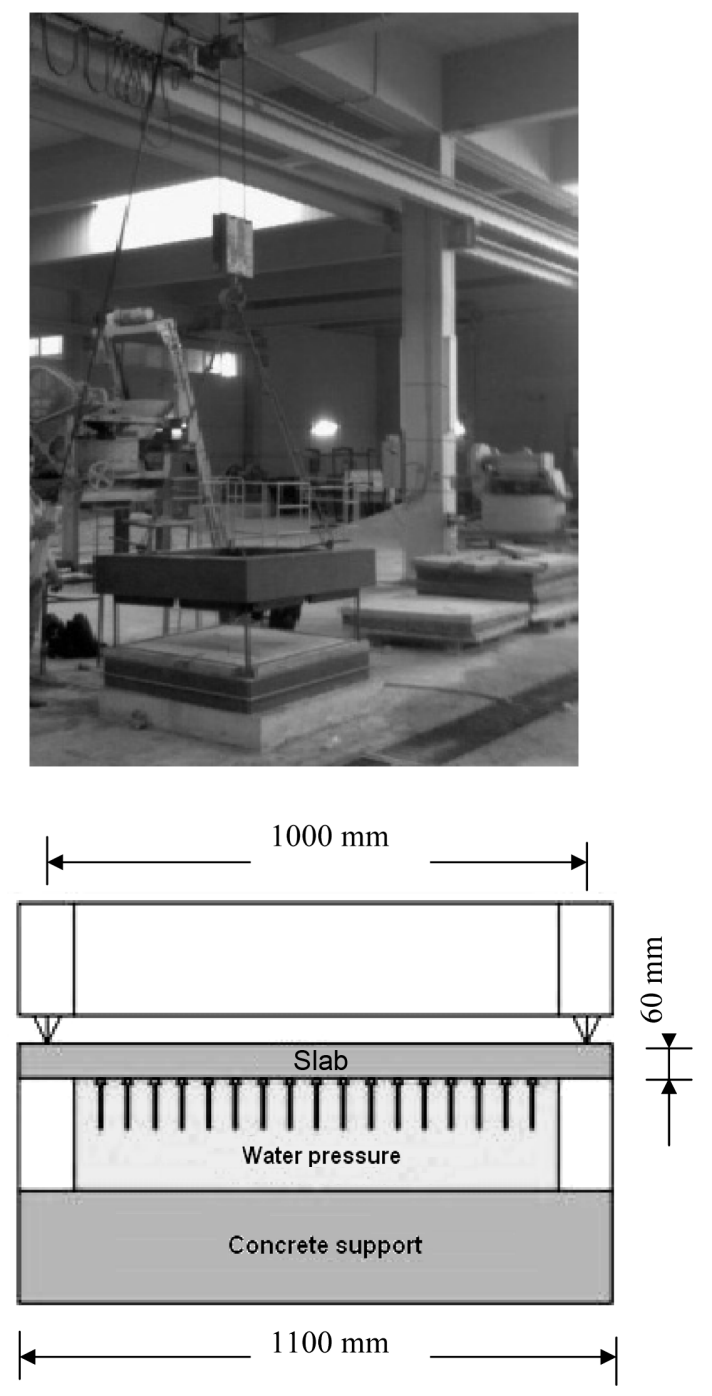

Fig. 5 Experimental set-up of the bending test using a uniformly distributed load.

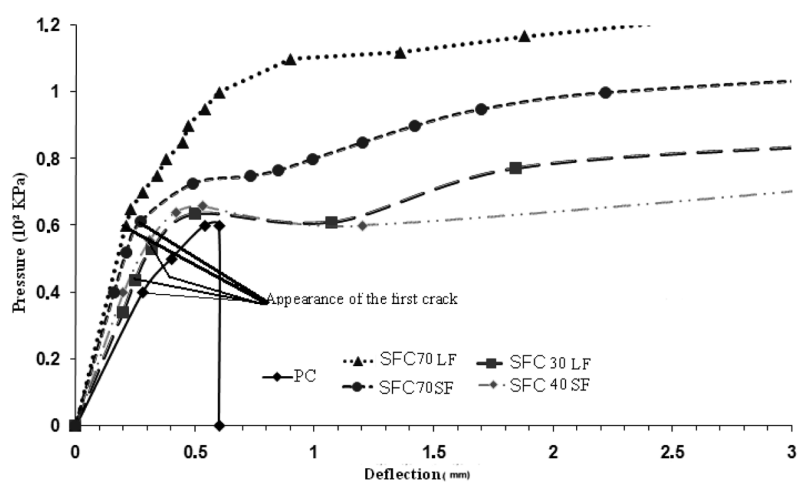

Fig. 6 Stress-deflection curves of the small slabs for small deflection.

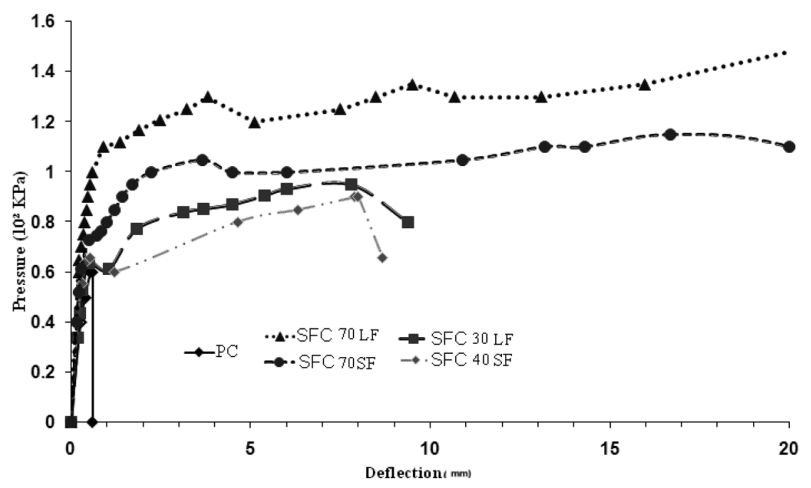

Fig. 7 Overall stress-deflection curves of the small slabs.

is indicated in Fig. 6 to distinguish the slopes of the elastic zone and the location of the appearance of the first crack in a better way (before the peak). This figure shows that fibers improve the failure strength and increase the maximum stress ( $83 \%$ for the $70 \mathrm{~kg} / \mathrm{m}^{3}$ density for LF fibers and $\approx 75 \%$ for SF). This figure also indicates an improvement of the elastic slope (especially for SF of about $20 \%$ ) and of the damaged elastic slope (especially for LF of about $15 \%$ ). Therefore, the SFC allows a decrease in deflection. To distinguish the slab behavior after the peak in a clearer way, the overall variation of stresses as a function of deflection is shown in Fig. 7. This figure shows that fibers improve the ductility and the deformation at and after failure, and in particular for the LF.

The results of Fig. 7 indicate the basic action of the fibers: their ability to transmit a force through the cracks, restrict their opening and decreasing the risk of debonding. Long fibers with a proportioning of $70 \mathrm{~kg} / \mathrm{m}^{3}$ give an improvement in maximum strength up to $100 \%$. The fibers are under tension starting at lower crack openings and provide the SFC a strength base post-cracking of high intensity. Nevertheless, beyond a certain crack opening, the fibers begin to break down one after the other and the SFC deteriorates.

The flexure behavior of slabs consists of several stages to be distinguished (Fig. 7):

- Linear elastic phase: In this first phase of loading, the slab behaves almost as a structure acquiring a linear elastic behavior.

- Cracking phase: As long as the strain hardening of the fibers anchorage does not occur, the crack opening is limited. As in the elastic phase, the bending moments in the uncracked areas do not increase anymore for the same load increment.

- Strain hardening phase: the anchorage of the fibers gradually 
Table 4 Deflection and peak load for the various tested slabs.

\begin{tabular}{c|c|c|c|c}
\hline Types & Deflection (elastic peak / max peak) & Peak load (elastic peak / max peak) & Deflection & Cracking load \\
\hline \hline PC & $0.54 /-$ & $0.6 /-$ & 0.28 & 0.4 \\
\hline SFC30LF & $0.50 / 7.80$ & $0.64 / 0.95$ & 0.25 & 0.44 \\
\hline SFC40SF & $0.53 / 6.33$ & $0.66 / 0.85$ & 0.3 & 0.56 \\
\hline SFC70LF & $0.90 / 3.24$ & $1.10 / 1.25$ & 0.23 & 0.62 \\
\hline SFC70SF & $0.49 / 3.65$ & $0.73 / 1.05$ & 0.27 & 0.62 \\
\hline
\end{tabular}

flows in the highest moment areas. The bending moment does not increase anymore, causing its redistribution more than in the previous phase.

- Failure phase: When lines of articulation have reached a developing stage, in such a way that the slab is transformed into an assemblage of substructures, a slight increase in loads leads to an unstable equilibrium leading to the collapse of the slab.

Similarly, Falkner et al. ${ }^{6}$ divided the strength and deformation behavior of PC and SFRC ground slab into three main regions. The first region is the uncracked state, where the slab showed a linear-elastic behavior. In the second region, the first crack occurred in the center of the slab, gradually developing, until the main cracks can be seen at the slab edges. The third region presented a redistribution of stresses within the slab until the plastic hinges occurred at the main cracks. After Falknet et al., ${ }^{6}$ and at this stage, the steel fiber was still able to maintain its slab action and the load was increased until ultimate failure occurred.

The peak load, the deflection and the cracking load are presented in Table 4 for the various tested slabs. This table shows a lower maximum peak for higher steel fiber dosage, with an increase in the maximum peak load. The reduction in deflection is more pronounced for the LF with a better capacity to close the mini cracks. Finally, the cracking load is increased for a higher steel fiber dosage, indicating a better strength.

Furthermore, test slabs at failure phase are presented in Figs. 8 and 9 for SFC30LF and for SFC70SF, respectively. Cracking patterns are typical of slab failure mode, with crack running from the center to the corner at $45^{\circ}$.

\section{Conclusions}

This experimental study allowed us to highlight the improvements on the concrete by adding steel fiber. The results showed

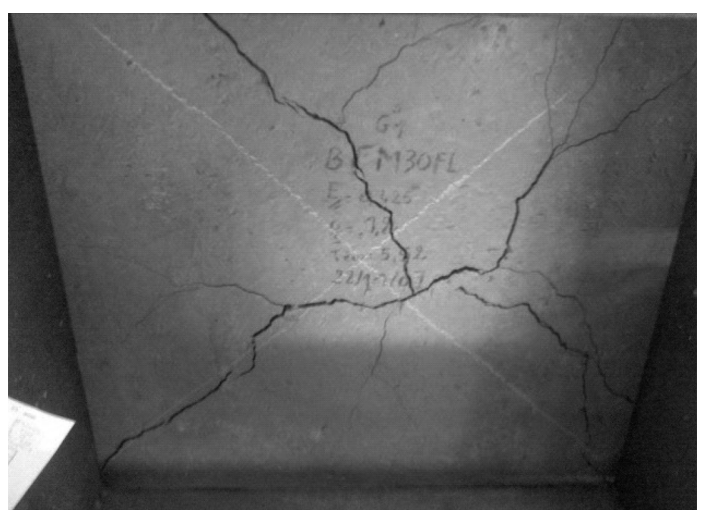

Fig. 8 Test slabs at failure phase for the SFC30LF.

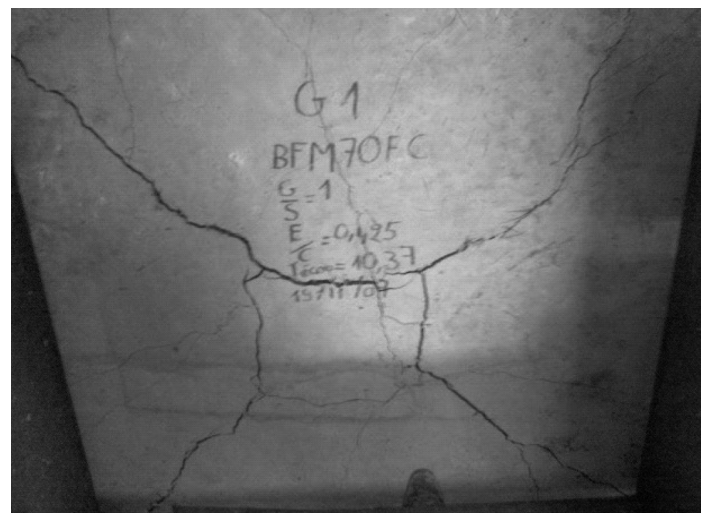

Fig. 9 Test slabs at failure phase for the SFC70SF. that:

1) The compressive strength of SFC increased up to $25 \%$ compared to PC, while the splitting tensile strength tensile tests showed an improvement of up to $45 \%$ of the SFC compared to PC.

2) The tests on small SFC slabs unveiled a lower deflection leading to an improvement in maximum strength (up to a 100\%), in the ductility and in resistance to cracking (up to 50\%).

3) The optimum size of the steel fibers recommended to act on the elastic zone (strength and cracking) or plastic zone (ductility and deformation) are different: In the elastic zone, the fibers must be numerous and small, while in the plastic zone, the fiber length must be large enough to ensure their proper anchorage in the matrix.

\section{Acknowledgments}

The authors wish to acknowledge the Tunisian Sika for providing the necessary fibers and admixtures. They also thank the National Engineering School of Gabes (and in particular Dr. M. Ltifi) for providing the necessary help to conduct slab testing. The authors would like also to thank professor Habib Abouda for proofreading the article.

\section{References}

1. Vondran, L., "Applications of Steel Fiber Reinforced Concrete," Concrete International, Vol. 13, No. 11, 1991, pp. 44 49.

2. Bakht, B. and Mufti, A., "FRC Deck Slabs without Tensile Reinforcement," Concrete International, Vol. 18, No. 2, 1996, pp. $50 \sim 55$.

3. Newhook, J. P. and Mufti, A. A., "A Reinforcing SteelFree Concrete Deck Slab for the Salmon River Bridge," Concrete International, Vol. 18, No. 6, 1996, pp. 30 34. 
4. Sargent, D. D., Ventura, C. E., Mufti, A. A., and Bakht, B., "Testing of Steel-free Bridge Decks," Concrete International, Vol. 21, No. 8, 1999, pp. 55 61.

5. Marti, P., Pfyl T., Sigrit, V., and Ulaga, T., "Harmonized Test Procedures for Steel Fiber-Reinforced Concrete," $A C I$ Materials Journal, Vol. 96, No. 6, 1999, pp. 676 686.

6. Destree, X., "Steel Fibre Reinforcement for Suspended Slabs," Concrete, Vol. 35, No. 8, 2001, pp. 58 59.

7. Ošlejs, J., "New Frontiers for Steel Fiber-Reinforced Concrete," Concrete International, Vol. 30, No. 5, 2008, pp. 45 50.

8. Falkner, H., Huang, Z., and Teutsch, M., "Comparative Study of Plain and Steel Fiber Reinforced Concrete Dground Slabs," Concrete International, Vol. 17, No. 1, 1995, pp. 45 51.

9. Barros, J. A. O. and Figueiras, J. A., "Flexural Behavior of SFRC: Testing and Modeling," Journal of Material in Civil Engineering, ASCE, Vol. 11, No. 4, 1999, pp. 331 339.

10. Khaloo, A. R. and Afshari, M., "Flexural Behaviour of Small Steel fibre Reinforced Concrete Slabs," Cement and Concrete Composites, Vol. 27, No. 1, 2005, pp. 141 149.

11. Sorelli, G, Meda, A., and Plizzarri, G. A., "Steel Fiber Concrete Slabs on Ground: A Structural Matter," ACI Structural Journal, Vol. 103, No. 4, 2006, pp. 551 558.
12. Rossi, P., Harrouche, N., and Belloc, A., "Méthode de Composition des Bétons de Fibres Métalliques," Annales de l'ITBTP, No. 475, 1989, pp. 38 43 (In French).

13. Rossi, P., Harrouche, N., and F. De Larrard, "Method for Optimizing the Composition of Metal-Fiber-Reinforced Concretes," Fiber Reinforced Cements and Concretes - Recent Developments, Swamy, R. N., and Barr, B., eds., Elseiver, Applied Science, 1989, pp. 1 10.

14. Rossi, P. and Harrouche, N., "Mix-Design and Mechanical Behavior of Some Steel-Fiber-Reinforced Concretes Used in Reinforced Concrete Structures," Materials and Structures, Vol. 23, 1990, pp. 256 266.

15. Rossi, P., "Steel Fiber Reinforced Concrete (SFRC): An example of French Research," ACI Materials Journal, Vol. 91, No. 3, 1994, pp. 273 279.

16. Rossi, P., "Les Bétons de Fibres Métalliques," Presses de l'ENPC Ed., Paris, 1998 (in French).

17. Rossi, P., "Le Développement Industriel des Bétons de Fibres Métalliques," Projet National BEFIM, Presses de l'ENPC Ed., Paris, 2002 (In French).

18. AFNOR, Essai de Traction par Flexion, NFP 18-406, 1981 (In French). 